\title{
Evidence and practice: a review of vignettes in qualitative research
}

Jayne Murphy, Jonathan Hughes, Sue Read, Sue Ashby

This is the authors' final version. The version of record is available at https://journals.rcni.com/nurse-researcher/evidence-and-practice/evidence-andpractice-a-review-of-vignettes-in-qualitative-research-nr.2021.e1787/abs 
Evidence and Practice

\title{
A review of vignettes in qualitative research
}

Jayne Murphy, Sue Read, Jonathan Hughes, Sue Ashby

Citation

Murphy J, Hughes J, Read S et al (2021) Evidence and practice: a review of vignettes in qualitative research. Nurse Researcher. doi: 10.7748/nr.2021/e1787

\begin{abstract}
Background: Developing and working through a $\mathrm{PhD}$ research study requires tenacity, continuous development and application of knowledge. It is paramount when researching sensitive topics to consider carefully the construction of tools for collecting data, to ensure the study is ethically robust and explicitly addresses the research question.
\end{abstract}

Aim: To explore how novice researchers can develop insight into aspects of the research process by developing vignettes as a research tool.

Discussion: This article focuses on the use of vignettes to collect data as part of a qualitative PhD study investigating making decisions in the best interests of and on behalf of people with advanced dementia. Developing vignettes is a purposeful, conscious process. It is equally important to ensure that vignettes are derived from literature, have an evidence base, are carefully constructed and peer-reviewed, and are suitable to achieve the research's aims.

Conclusion: Using and analysing a vignette enables novice researchers to make sense of aspects of the qualitative research process and engage with it to appreciate terminology. 
Implications for practice: Vignettes can provide an effective platform for discussion when researching topics where participants may be reluctant to share real-life experiences due to their sensitive nature.

\section{Author Details}

* Jayne Murphy, Senior Lecturer University of Wolverhampton, Wulfruna Street, Wolverhampton WV11LY (* contact)

Dr Jonathan Hughes, Senior Lecturer in Ethics, Keele University, Staffordshire, UK ST5 5BG

Professor Sue Read, Emerita Professor of Learning Disability Nursing, Keele University, Staffordshire, UK ST5 5BG

Dr Sue Ashby, Honorary Lecturer, Keele University, Staffordshire, UK ST5 5BG

Keywords: data collection, instrument design, interviews, methodology, narrative, qualitative research, research, research methods, study design

\section{Introduction}

Qualitative research is concerned with participants' experiences of phenomena. Qualitative researchers should use methods that result in open expression by participants, without constraint. Interviewing is a frequently used method of gathering participants' experiences, perceptions, opinions, feelings and knowledge (Austin and Sutton 2014).

Vignettes - sometimes referred to as case studies (Stacey et al 2014, Moffat et al 2016) - are short stories about a hypothetical person or people that are used in qualitative and quantitative research to glean information about participants' beliefs (Gourlay et al 2014). They present fictional or fictionalised scenarios (Bloor and Wood 2011) and research participants are asked to comment on how they feel they would have acted or how they feel a third party should act in these scenarios (Miller and Brewer 2003, Gourlay et al 2014). They are often used in qualitative research and social survey research (Miller and Brewer 2003), and can generate frank and 
extensive interview material (Sampson and Johannessen 2020). They are especially valuable in exploring perceptions, attitudes and behaviours (Hughes 2008).

Qualitative research resembles an archaeological excavation and is a never-ending journey for many researchers, not just novices (Kalman 2019). Improved understanding is achieved by the iterative process in which the researcher gets closer to the phenomenon studied (Aspers and Corte 2019). However, it is often challenging for the novice researcher, particularly in terms of the skills needed and the analysis of the data generated (Lewis 2018).

This article will discuss how sharing the experience of devising, refining and using vignettes can often help novice researchers and inform future research practice and methodology.

\section{Background}

People with advanced dementia are likely to be cognitively compromised and unable to make informed choices about healthcare treatments. They are therefore reliant on others to make decisions in their best interests concerning healthcare treatments. Many countries have legislation, advisory policy and practice guidance governing decision-making for incapacitated people - in England and Wales, the governing legislation is the Mental Capacity Act 2005.

The literature suggests that 'best interests' decisions are often clinically driven, with professionals selectively choosing when to involve families (Dreyer, Fort and Nortvedt 2010; House of Lords Select Committee 2014; Kong and Ruck-Keane 2019). The best interests principle is often used as a tool to justify safeguarding decisions that may be made for reasons other than safeguarding (House of Lords Select Committee 2014). 
Research that explores perspectives of best interests is limited in dementia care. Williams et al (2012) recommended that further research be conducted to understand better the different perspectives of those involved in 'best interests' decisions.

\section{The main strengths and limitations of vignettes}

Table 1 identifies the main strengths and limitations of vignettes identified in the literature.

A literature search was conducted using the following search terms: dementia, best interests and knowledge, best interests and dementia, best interests, nurses' knowledge and understanding. All articles published in PubMed, Academic Search complete, CINAHL, MEDLINE, PsychINFO and Cochrane Library databases were searched. Empirical research and theoretical research was identified and evaluated for its relevance to the research search terms and how it could inform the research process. The search results revealed a variety of studies that focused on best interests and/or dementia but focus on nurses' knowledge or perspectives was limited. The results also revealed a number of studies that utilised vignettes as a research tool.

Vignettes are variously described as a research methodology (O'Dell et al 2012, Aldersey et al 2016), a research method (Lapatin et al 2012, Bradbury-Jones et al 2014) or a research tool (Jenkins et al 2010). Stokes and Schmidt (2012) described vignettes as a tool used in and that supports the survey method of qualitative, exploratory research.

Alexander and Becker (1978) provided early support for vignettes in research, considering them to produce more reliable measures of participants' opinions than typical abstract survey questions. Finch (1987) acknowledged that interview responses were too abstract and derived from participants' general perspectives, so 
did not correlate well with studies of people's attitude. Alexander and Becker (1978) and Finch (1987) both suggested that vignettes could provide a stimulus for discussion about real life.

Vignettes enable participants to convey a range of perspectives from the points of view of the vignettes' characters, their peers and people more generally, or from their personal viewpoints or a combination of perspectives (Hughes 2008). They enable researchers to be flexible in how they present complex environments and provide the opportunity to highlight variables related to the topic (Aldersey et al 2016).

Using participants as informants and gathering responses from the perspective of a third person provides an immediate distancing effect that can be beneficial when exploring potentially sensitive topics; this may help minimise socially desirable reporting patterns (Finch 1987, Hughes 2008). Interviews may raise issues that interviewees find distressing (King and Horrocks 2010). Vignettes can be a less personal and therefore less threatening way of exploring sensitive topics (Barter and Renold 1999, Schwappach et al 2013). They can be useful in providing distance between the researcher and participants, enabling the researcher to explore the participants' views without requiring them to disclosure anything personal (BradburyJones et al 2014, Kandemir and Budd 2018). Normalisation of the topic being researched through using vignettes may encourage participants to reveal personal experiences when they feel comfortable to do so (Gourlay et al 2014).

As with other forms of survey research, vignettes have limitations (Aldersey et al 2016). Sources of contention are whether participants' responses to vignettes are representative of or generalisable to their behaviour, although this is an issue for qualitative research generally. Bloor and Wood (2011) said that vignettes should not be thought of as matches for real-life experiences and responses as reportage of 
behaviour in real-life situations; instead, they are a useful guide to group norms and beliefs. Finch (1987) said that researchers should not make assumptions about how participants might act based on what they have said about vignettes. However, West (1982) said that vignettes capture something approximating a real-life situation - they are lifelike and therefore likely to predict behaviour. Stacey et al (2014) said that the behaviour demonstrated by health professionals in simulated situations will closely resemble their behaviour in the equivalent clinical situations. Thalén et al (2017) said that although vignettes of clinical situations have been criticised, decision-making regarding a hypothetical situation reflects decision-making in real life. The debate around whether simulation reflects actual behaviours should be recognised and acknowledged as a potential limitation.

Another important criticism is that the 'vignette world' is too simple compared to the real world. Vignettes omit the wide spectrum of issues that people face and respond to in their everyday lives, so may oversimplify situations and produce unrealistic results (Hughes 2008). They also have the potential for hypothetical bias - differences between intentions and actual behaviours - and may not initiate the emotional responses that real-life situations evoke (Schwappach et al 2013). However, this is also a distancing effect and therefore a possible benefit (Hughes 2008). Participants may also feel uncomfortable discussing their personal situation and may disguise the truth about their own actions or beliefs.

If vignettes are too detailed or too complex or if the researcher uses too many, participants may lose the thread of what is being discussed, disengage (Finch 1987) or tire (Hughes 2008). Using a series of static vignettes risks participants drawing on the context of the previous vignette for the next vignette (Alexander and Becker 1978, Hughes 2008). 
West (1982) discussed the design of vignettes: they can be sparse in detail or ambiguous so that participants have to 'fill in' details themselves; alternatively, they can be sufficiently detailed in some areas, while lacking in others, so that participants have enough information to formulate an opinion while still questioning or surmising about the missing details. A vignette therefore requires careful consideration in its construction, if it is to achieve the aims of the research.

It can be difficult to interpret responses when participants shift between discussing the vignettes as themselves, the vignettes' characters and what ought to happen (O'Dell et al 2012). Responses to vignettes may also be influenced by participants' perceptions of what is socially desirable, particularly when participants are asked how they would act in the scenario presented (Gourlay et al 2014, Aldersey et al 2016).

Researchers therefore have a degree of power when designing vignettes. For instance, being aware of potential challenges can inform the design of the questions associated with a vignette, as well as the analysis of the responses, with researchers considering whether participants' responses represent their real thoughts about a scenario.

\section{Designing vignettes}

Table 2 consolidates suggestions that were helpful when designing a vignette to ensure it was fit for purpose.

The lead author chose to use vignettes in her doctoral study, as Willner et al (2011) and Greener et al (2012) both used vignettes in studies of 'best interests' judgements - Willner et al (2011) explored the state of knowledge of nurses, therapists and psychiatrists around mental capacity issues and Greener et al (2012) explored conceptual tensions for those involved in decision-making in respect of places of residence. She devised two vignettes that involved decisions about the initiation and 
continuation of treatment for patients with advanced dementia. The vignettes depicted scenarios common for people with dementia, where treatment options needed to be considered and 'best interests' standards applied. The aim was to elicit responses from nurses who were the research participants about what they would do in the given situation and what they thought should be done. The vignettes were further developed through constructive supervisory discussions and consultation with professionals with expertise in 'best interests' assessments, research using vignettes or experience of the care of patients with significant nursing needs and impaired capacity, including advanced dementia.

Many researchers have advocated varying the characters in vignettes by factors such as age, gender and race, to identify any characteristics that might trigger a particular response from participants (Lapatin et al 2012). Finch (1987) also found that varying some circumstances was beneficial. If the interview questions are constructed well and the vignette is constructed well, then it is straightforward to establish the factors that might influence the response. This also adds to the validity and reliability of the vignette as a tool for collecting data - if participants might draw inferences from a character's specific qualities, changing the qualities and comparing responses from a choice of personal attributes or qualities might increase the validity of the responses presented.

Interview questions were devised that were associated with the vignettes' content, as associated questions are especially useful when trying to measure complex concepts best described using examples (Vargas 2011). Details about the characters in the vignettes were therefore changed, following a pilot study with five participants, to establish if participants' responses would be different when the details of the 
characters in the vignettes were different. Responses were consistent, which was useful when analysing them.

Several participants discussed personal experiences, to underpin the rationales for their proposed decisions. This is a potential pitfall (Gourlay et al 2014), as participants may veer off topic and debate their own experiences, particularly if the researcher is not prepared for this possibility. However, the inclusion of personal experiences enriched the responses and the interpretation of the data could take account of this as the responses were analysed. Socially desirable responses (Gourlay et al 2014) were also limited, as participants acknowledged the ethical uncertainties of their perspectives and so appeared to indicate honesty in their responses.

A significant number of participants recognised in their discussion of one vignette what they thought should happen with a patient (normative) and what they would recommend themselves (descriptive). The vignette described quality of life indicators and the participants proposed that the patient had something to live for, as there was evidence of enjoyment in her life. For example, one participant expressed that: 'Despite her poor condition Kashi still enjoys her music, she smiles at Vic and appears to enjoy his company each day. She holds his hand as he sings along to music, where Kashi will swing her hand in time to Vic's voice.' There was no statistical difference in responses when the character's name and gender were different.

Although the vignettes were about the sensitive issue of decision-making on behalf of people with advanced dementia, they helped the study to explore participants' views, without the participants having to think about their personal or professional experiences (Bradbury-Jones et al 2014).

It is a challenge to establish when data saturation has been achieved in any research that uses interviews to collect data - this is when further data collection or analysis is 
unnecessary, given the data already collected or analysed in the study (Saunders et al 2018). Data saturation is an elastic notion, as there is no quantifiable guide to the correct number of participants for a study and new data will always add something new, even if there are diminishing returns (Tran et al 2016); individual participants contributing to research in isolation will provide responses that are as individual as they are. But using vignettes may help with this. In the example study, the lead author felt before beginning the interviews that data saturation would be a difficult concept to judge; however, in practice, transcribing and analysing the data in parallel with conducting the interviews meant it became quite obvious, with data saturation and its meaning becoming clearer and the value of the participants' responses beginning to take shape, making the concept of data saturation more concrete and recognisable.

\section{Conclusion}

This article has discussed how developing vignettes for a research study is an iterative process that should be informed by the literature to avoid any potential challenges and ensure that vignettes are well constructed. The lead author used vignettes as the empirical component of a PhD study exploring the experiences of registered nurses of 'best interests' decision-making in advanced dementia. Using vignettes provided an opportunity for her to develop research skills while advancing the research's aims.

The research process can be challenging to navigate and reviewing literature is not always sufficient to enable researchers to apply the chosen techniques. Vignettes are powerful tools that can be applied to sensitive research, but the researcher needs to be able to construct, develop and use them. Supervisory discussions can assist in their development, as can piloting the vignettes to strengthen the validity of the approach. 
Involvement in research and using different tools of research adds a further layer of development. In addition to studying the literature and obtaining feedback from supervisors and experts, the research process enables the novice researcher to contextualise the research process and promotes the development of knowledge. Exploring the definition, structure, development of and reliable use of vignettes in research creates engagement with the research process, increasing understanding, knowledge and confidence.

Table 1: Strengths and limitations of using vignettes

\begin{tabular}{|l|l|}
\hline Strengths of using vignettes & Limitations of using vignettes \\
\hline Provide a stimulus of discussion of real- & 'Vignette world' may be different to 'real \\
life & world' \\
\hline Allow for specific content on which to & May over-simplify situations, providing \\
express thoughts & unrealistic results \\
\hline Allow researchers to simplify complex & May initiate 'socially desirable' \\
scenarios and highlight variables & responses from participants \\
\hline Allow for distancing to avoid discomfort & There may be an absence of emotional \\
over sensitive topics & resonance for participants \\
\hline
\end{tabular}

Table 2: Checklist for designing and strengthening a vignette

\begin{tabular}{|l|l|}
\hline $\begin{array}{l}\text { The vignette should be } \\
\text { (recommended in the literature) }\end{array}$ & Demonstrated by \\
\hline $\begin{array}{l}\text { Based on research findings and } \\
\text { context-specific }\end{array}$ & $\begin{array}{l}\text { The construction of vignettes that describe reality } \\
\text { and are valid can be done by reviewing the }\end{array}$ \\
\hline
\end{tabular}




\begin{tabular}{|l|l|}
\hline & $\begin{array}{l}\text { empirical literature or by consulting experts } \\
\text { (Heverly, Fitt and Newman 1984). }\end{array}$ \\
\hline Devised with expert consultation & $\begin{array}{l}\text { Vignettes should be vetted experts who can } \\
\text { judge their suitability for the study (Gould 1996) }\end{array}$ \\
\hline True to life & $\begin{array}{l}\text { A vignette must simulate certain aspects of real- } \\
\text { world scenarios, bearing some resemblance to } \\
\text { situations encountered by the participants (Evans } \\
\text { et al 2015). }\end{array}$ \\
\hline Concise, readable and easy & to \\
understand & $\begin{array}{l}\text { Carefully written and edited, clear and brief. } \\
\text { Overly long vignettes risk the participant failing to } \\
\text { respond (Veloski et al 2005) }\end{array}$ \\
\hline Piloted & $\begin{array}{l}\text { It is important to pilot the vignette before data } \\
\text { collection begins, usually on a small sample of } 5 \\
-10 \text { participants (Gray, Royall, Maison 2017) }\end{array}$ \\
\hline
\end{tabular}




\section{References:}

Aldersey HM, Chinh Huynh D, Whitley R (2016) A systematic examination of the nature and content of vignettes in schizophrenia research. Journal of Mental Health. 25, 3, 189-196. doi: 10.3109/09638237.2015.1057325.

Alexander CS, Becker HJ (1978) The use of vignettes in survey research. Public Opinion Quarterly. 42, 1, 93-104. doi: 10.1086/268432.

Aspers $P$, Corte $U$ (2019) What is qualitative in qualitative research? Qualitative Sociology. 42, 2, 139-160. doi: 10.1007/s11133-019-9413-7.

Austin Z, Sutton J (2014) Qualitative research: getting started. The Canadian Journal of Hospital Pharmacy. 67, 6, 436-440. doi: 10.4212/cjhp.v67i6.1406.

Barter C, Renold E (1999) The Use of Vignettes in Qualitative Research. http://sru.soc.surrey.ac.uk/SRU25.html (Last accessed: 9 March 2021.)

Bloor M, Wood F (2011) Keywords in Qualitative Methods: A Vocabulary of Research Concepts. Sage Publications, Riverside County CA, 183-184.

Bradbury-Jones C, Taylor J, Herber OR (2014) Vignette development and administration: a framework for protecting research participants. International Journal of Social Research Methodology. 17, 4, 427-440. doi: 10.1080/13645579.2012.750833.

Dreyer, A. Forde, R. Nortvedt, P. (2010) Life-prolonging treatment in nursing homes: how do physicians and nurses describe and justify their own practice? Journal of Medical Ethics. 36 pp: $396-400$.

Evans SC, Roberts MC, Keeley JW et al (2015) Vignette methodologies for studying clinicians' decision-making: validity, utility, and application in ICD-11 field studies. International Journal of Clinical and Health Psychology. 15, 2, 160-170. doi: 10.1016/j.ijchp.2014.12.001.

Finch $\mathrm{J}$ (1987) The vignette technique in survey research. Sociology. 21, 1, 105-14. doi: $10.1177 / 0038038587021001008$.

Gray D, Royall B, Maison H (2017) Hypothetically speaking: using vignettes as a stand alone qualitative method. In Braun V, Clarke V, Gray D (Eds) Collecting Qualitative Data: A Practical Guide to Textual and Virtual Techniques. Cambridge University Press, Cambridge, 45-70.

Greener H, Poole M, Emmett C et al (2012) Value judgements and conceptual tensions: decision-making in relation to hospital discharge for people with dementia. Clinical Ethics. 7, 4, 166-174. doi: 10.1258/ce.2012.012028.

Gould D (1996) Using vignettes to collect data for nursing research studies: how valid are the findings? Journal of Clinical Nursing. 5, 4, 207-212. doi: 10.1111/j.13652702.1996.tb00253.x. 
Gourlay A, Mshana G, Birdthistle I et al (2014) Using vignettes in qualitative research to explore barriers and facilitating factors to the uptake of prevention of mother-to-child transmission services in rural Tanzania: a critical analysis. BMC Medical Research Methodology. 14, 21. doi: 10.1186/1471-2288-14-21.

Heverly MA, Fitt DX, Newman FL (1984) Constructing case vignettes for evaluating clinical judgment: an empirical model. Evaluation and Program Planning. 7, 1, 45-55. doi: 10.1016/0149-7189(84)90024-7.

House of Lords Select Committee (2014) Mental Capacity Act 2005: Post-Legislative Scrutiny. The Stationery Office, London.

Hughes R (2008) Vignettes. In Given L (Ed) The Sage Encyclopedia of Qualitative Research Methods. Sage Publications, Thousand Oaks CA, 919-920.

Jenkins N, Bloor M, Fischer $\mathrm{J}$ et al (2010) Putting it in context: the use of vignettes in qualitative interviewing. Qualitative Research. 10, 2, 175-198. doi: $10.1177 / 1468794109356737$.

Kalman M (2019) 'It requires interest, time, patience and struggle': novice researchers' perspectives on and experiences of the qualitative research journey. Qualitative Research in Education. 8, 3, 341-377. doi: 10.17583/qre.2019.4483.1

Kandemir K, Budd R (2018) Using vignettes to explore reality and values with young people. Forum. 19, 2. doi: 10.17169/fqs-19.2.2914.

King N, Horrocks C (2010) Interviews in Qualitative Research. Sage Publications, London.

Kong, C. Ruck Keene, A. (2019) Overcoming Challenges in the Mental Capacity Act 2005. London: Jessica Kingsley Publishers.

Lapatin S, Gonçalves M, Nillni A et al (2012) Lessons from the use of vignettes in the study of mental health service disparities. Health Service Research. 47, 3pt2, 13451362. doi: 10.1111/j.1475-6773.2011.01360.x.

Lewis $L$ (2018) Finding the stories: a novice qualitative researcher learns to analyse narrative inquiry data. Nurse Researcher. 21, 26, 14-18. doi: 10.7748/nr.2018.e1578.

Miller RL, Brewer JD (Eds) (2003) The A-Z of Social Research. Sage Publications, London.

Moffat S, Skinner J, Fritz Z (2016) Does resuscitation status affect decision making in a deteriorating patient? Results from a randomised vignette study. Journal of Clinical Evaluation. 22, 6, 917-923. doi: 10.1111/jep.12559.

O'Dell L, Crafter S, de Abreu G et al (2012) The problem of interpretation in vignette methodology in research with young people. Qualitative Research. 12, 6, 702-714. doi: $10.1177 / 1468794112439003$. 
Sampson H, Johannessen IA (2020) Turning on the tap: the benefits of using 'real-life' vignettes in qualitative research interviews. Qualitative Research. 20, 1, 56-72. doi: $10.1177 / 1468794118816618$.

Saunders, B, Sim J, Kingstone T et al (2018) Saturation in qualitative research: exploring its conceptualization and operationalization. Quality and Quantity. 52, 4, 1893-1907. doi: 10.1007/s11135-017-0574-8.

Schwappach DL, Frank O, Davis RE (2013) A vignette study to examine health care professionals' attitudes towards patient involvement in error prevention. Journal of Evaluation in Clinical Practice. 19, 5, 840-848. doi: 10.1111/j.13652753.2012.01861.x.

Stacey D, Brière N, Robitaille $\mathrm{H}$ et al (2014) A systematic process for creating and appraising clinical vignettes to illustrate interprofessional shared decision making. Journal of Interprofessional Care. 28, 5, 453-459. doi: 10.3109/13561820.2014.911157.

Stokes J, Schmidt G (2012) Child protection decision making: a factorial analysis using case vignettes. Social Work. 57, 1, 83-90. doi: 10.1093/sw/swr007.

Thalén L, Heimann Mählenbock K, Almkvist O et al (2017) Do adapted vignettes improve medical decision-making capacity for individuals with Alzheimer's disease? Scandinavian Journal of Psychology. 58, 6, 497-503. doi: 10.1111/sjop.12401.

Tran V-T, Porcher R, Falissard B et al (2016) Point of data saturation was assessed using resampling methods in a survey with open-ended questions. Journal of Clinical Epidemiology. 80, 88-96. doi: 10.1016/j.jclinepi.2016.07.014.

Vargas P (2011) Vignette question. In Lavrakas PJ (Ed) Encyclopedia of Survey Research Methods. Sage Publications, Thousand Oaks CA, 948-949.

Veloski J, Tai S, Evans AS et al (2005) Clinical vignette-based surveys: a tool for assessing physician practice variation. American Journal of Medical Quality. 20, 3, 151-157. doi: $10.1177 / 1062860605274520$.

West P (1982) Reproducing Naturally Occurring Stories: Vignettes in Survey Research. Medical Research Council Social and Public Health Sciences Unit, Aberdeen.

Williams V, Boyle M, Jepson M et al (2012) Making Best Interests Decisions: People and Processes. Mental Health Foundation, London.

Willner $P$, Jenkins $R$, Rees $P$ et al (2011) Knowledge of mental capacity issues in community teams for adults with learning disabilities. Journal of Applied Research in Intellectual Disabilities. 24, 2, 159-171. doi: 10.1111/j.1468-3148.2010.00573.x. 